\title{
Assessment of International Frontal Sinus Anatomy Classification among senior residents through inter- and intra-rater reliability
}

Kholood Assiri, MD, ORL-HNS SB, Abmad Alroqi, MD, ORL-HNS,

Turki Aldrees, MD, ORL-HNS SB, Sharif Almatrafi, MD, ORL-HNS SB.

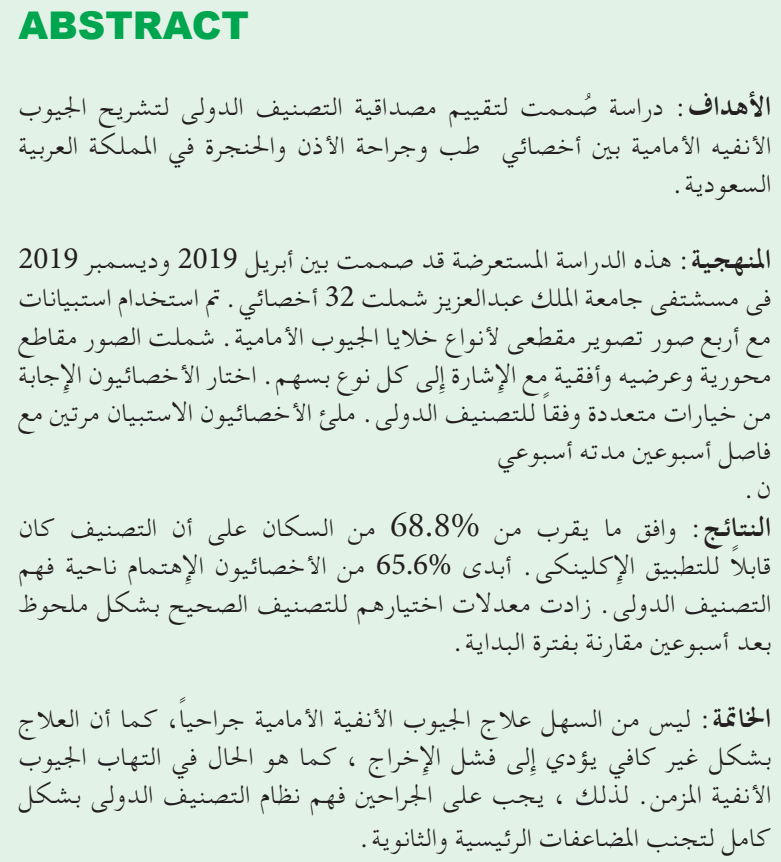

Objectives: To evaluate the International Frontal Sinus Anatomy Classification (IFAC) reliability among Saudi board otorhinolaryngology senior residents.

Methods: This cross-sectional study was carried out at King Abdulaziz University Hospital, Riyadh, Saudi Arabia between April 2019 and December 2019, included 32 senior residents. Questionnaires with 4 computed tomography images showing the different frontal cell types were used in this survey. All scans included 3 planes (axial, sagittal, coronal) and the tested cell was marked with arrows. Residents chose the answer from multiple choices according to the IFAC system. All residents filled the same questionnaire twice with 2 weeks interval.

Results: Approximately $68.8 \%$ of residents agreed that the classification was applicable clinically. The resident's attitude toward the importance of understanding IFAC was $65.6 \%$. Residents' correct classification of the marked cells increased significantly for most of the questions from baseline to 2 weeks.

Conclusion: The frontal sinus is not easy to treat surgically, and its inadequate treatment causes the failure of drainage, as in the case of chronic rhinosinusitis. Therefore, surgeons must fully understand the IFAC system to avoid major and minor complications.

Keywords: frontal sinus, International Frontal Sinus Anatomy Classification, otolaryngology residents, computed tomography, chronic rhinosinusitis

Saudi Med J 2020; Vol. 41 (5): 466-472 doi: 10.15537/smj.2020.5.25071

From the Department of Otorhinolaryngology (Assiri, Alroqi), King Abdulaziz University Hospital, Riyadh; and from the Department of Otolaryngology-Head and Neck Surgery (Aldrees and Almatrafi), College of Medicine, Prince Sattam bin Abdulaziz University, Alkharj, Kingdom of Saudi Arabia.

Received 23rd December 2019. Accepted 7th April 2020.

Address correspondence and reprint request to: Dr. Kholood Assiri, Department of Rhinology and Skull Base Surgery, King Abdulaziz University Hospital, Riyadh, Kingdom of Saudi Arabia. E-mail:dr.kholood1@hotmail.com

ORCHID ID: https://orcid.org/0000-0002-0856-0729

Chronic rhinosinusitis (CRS), is a sinonasal mucosa $\bigcup_{\text {status characterized by inflammation, presents }}$ with symptoms of nasal blockage, mucopurulent discharge, decreased smell sensation, and facial pain or pressure. $^{1-3}$ The recently published American Academy of Otolaryngology Clinical Practice Guideline defines CRS as 2 or more typical symptoms mentioned above that persists for 12 weeks or longer, with one or more documented evidence of inflammation as follows; 1) purulent discharge or edema in the middle meatus, 2) polyps, and 3) positive imaging signs declaring 
opacification or swelling of the sinus mucosa. ${ }^{4}$ The best management plan of CRS includes the use of antibiotics, topical or systemic steroids, anti-inflammatory agents, and antihistaminic drugs. However, if the condition resists medical management, endoscopic sinus surgery becomes the ideal choice. ${ }^{4}$

The frontal sinus location behind and above the frontal beak necessitates an angulated endoscopic approach; thus, it is difficult to reconnoiter it surgically. Inadequate surgical clearance of the frontal sinus drainage pathway is a common reason for endoscopic frontal sinus surgery (EFSS) failure in CRS. To avoid complications or surgical failure related to the frontal sinus, the surgeon needs to conceptualize the anatomy fully and draft a surgical plan. This approach will allow adequate preparation and precise placement of dissecting instruments with minimal risk while enabling complete clearance of the frontal recess and frontal ostium.

Many classification systems aim to assort the different air cells in the frontal area. However, a system that addresses both the number and position of air cells and its effect on the frontal drainage passage will assist in understanding the surgical anatomy and approach. The International Frontal Sinus Anatomy Classification (IFAC) system, a consensus document, provides expert opinion on how to treat frontal sinus diseases based on computed tomography (CT)-based classification of frontal air cells (Appendix 1). Thus, the evaluation of the anatomy and pathway of the frontal sinus requires access to high-quality CT scans. To date, only a single study has assessed the inter- and intra-rater reliability of the IFAC system among an international class of rhinologists by using different analytical methods. ${ }^{5}$ The study reports pairwise inter-rater reliability of 0.72 to 1.0 (mean: 0.92 , SD [standard diviation]: 0.05 ), intraclass correlation coefficient (ICC) of 0.98 , intra-rater reliability $(\kappa)$ of 0.86 to 1.0 (mean: 0.94 , SD: 0.04), and within-rater ICC of 0.98. Therefore, this study aimed to assess the reliability and consistency of the use of the IFAC system among otorhinolaryngology residents.

Methods. This cross-sectional questionnaire-based study was performed in King Abdulaziz University Hospital, Riyadh, Saudi Arabia between April 2019 and December 2019. The inclusion criteria

Disclosure. Authors have no conflict of interests, and the work was not supported or funded by any drug company. included otorhinolaryngology-head and neck surgery (ORL-HNS) senior residents of the King Saud University, Riyadh, Saudi Arabia. The study protocol was checked and signed by the Institutional Review Board, Medicine Research Center, King Saud University (reference number 19/4036/IRB). The study has also followed the Helsinki declaration. Each questionnaire included 4 CT images showing different types of frontal cells. Each CT image presented all 3 planes (axial, sagittal, coronal), and arrows were used to indicate air cells. The residents were asked to choose the best answer from the choices according to the IFAC system (Figure 1). Other questions were developed as needed to gather necessary information. The primary investigator distributed the questionnaire during resident-education activities and subsequently collected the data. A second questionnaire was filled after a 2-week interval. The residents were asked to fill out the questionnaire by themselves and hand it to the primary investigator.

Scoring comprised of one point for correct classification or response and zero points for incorrect classification by the resident. The overall classification score was calculated by summing the discrete scores for the 7 images. The overall resident score of less than $60 \%$ (4 correct answers or less) was considered to be poor classification grade.

Statistical analysis. Statistical analysis of coded data was performed through the IBM SPSS Statistics for Windows, version 22 (IBM Corp, Armonk, NY, USA). Continuous variables were expressed as mean and SD, while categorical variables as percentages. Statistical significance was set at $p \leq 0.05$. Association between residents' characteristics and their classification accuracy was tested using the Fisher exact probability test due to small frequency cells. Inter/intra-rater reliability and rate of the agreement were assessed by intraclass correlation and Cohen's kappa (к) for all possible rater pairs.

Results. The study included 32 residents (male, $81.3 \%$ ) with a mean age of $29.8 \pm 1.4$ (range, 27 to 34 ) years. More than half $(53.1 \%)$ of the included residents were in their 4th year of training (R4) (Table 1).

Table 2 demonstrated the attitude of the residents regarding the IFAC and was measured twice with a 2 -week interval. At baseline, $40.6 \%$ of residents agreed that the classification is applicable clinically, and this agreement rate increased significantly to $68.8 \%$ after 2 weeks $(p=0.035)$. The residents' agreement rate on the importance of IFAC to understand the EFSS approach increased significantly from $37.5 \%$ at baseline to $71.9 \%$ after 2 weeks $(p=0.001)$. Approximately $40.6 \%$ of residents agreed that IFAC enabled consistent 


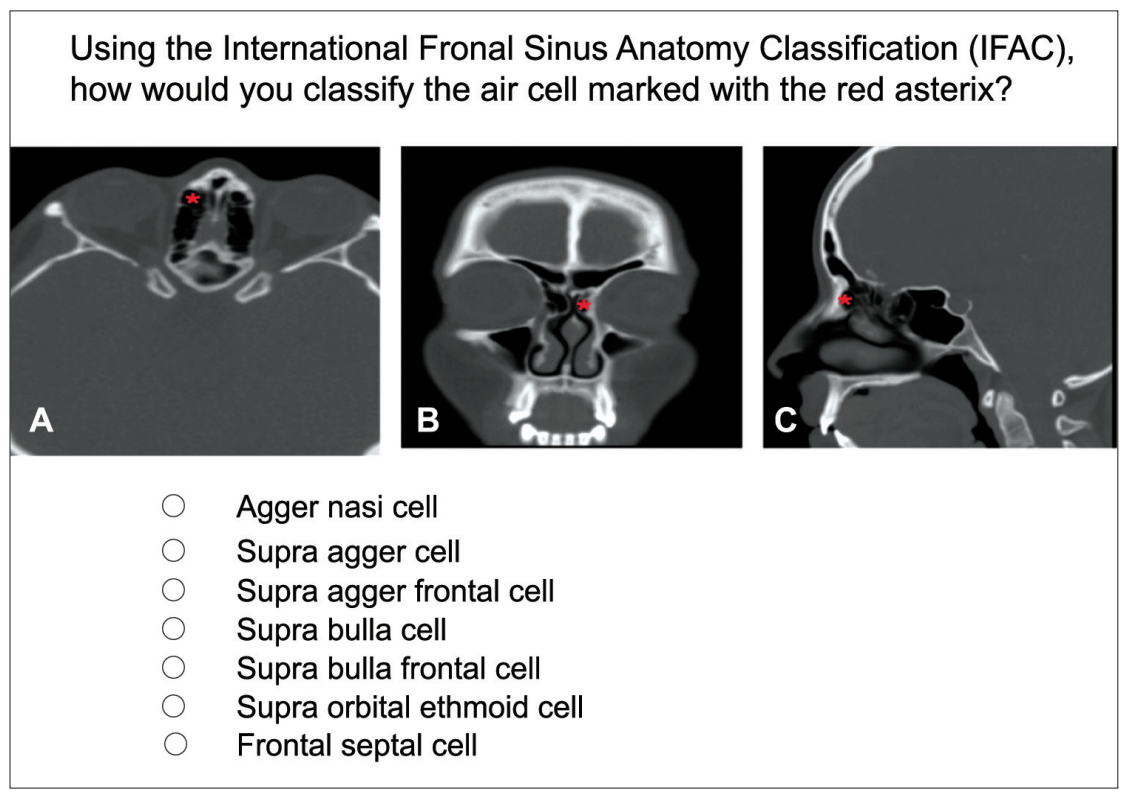

Figure 1 - Computed tomography scan of a single agger nasi cell showing the A) axial plane, B) coronal plane, C) sagittal plane

Table 1 - Basic data of otolaryngology-head and neck surgery senior residents.

\begin{tabular}{lrl}
\hline Characteristics & $\mathbf{n}$ & $(\%)$ \\
\hline Age, years & & \\
$\quad<30$ years & 15 & $(46.9)$ \\
$\quad>30$ years & 17 & $(53.1)$ \\
Gender & & \\
$\quad$ Male & 26 & $(81.3)$ \\
Female & 6 & $(18.8)$ \\
Residency level & & \\
R4 & 17 & $(53.1)$ \\
R5 & 15 & $(46.9)$ \\
\hline
\end{tabular}

communication between otorhinolaryngologist residents, and this agreement improved significantly to $71.9 \%$ in the second questionnaire $(p=0.002)$. The resident's attitude toward the importance of understanding the classification system improved from $37.5 \%$ at baseline to $65.6 \%$ after 2 weeks ( $p=0.012$ ).

Regarding residents' correct classification of the marked cells (Table 2), the classifcation of agger nasi cell is not signifcantly different between the first and second questionnaire $(p=0.715)$. The classification of supra agger cell, improved significantly from 53.1\% for questionnaire one to $87.5 \%$ for questionnaire $2(p=0.002)$. Supra agger frontal cell, was correctly classified by $43.8 \%$ residents at baseline and improved significantly $81.3 \%$ after 2 weeks $(p=0.001)$. The classification of supra bulla cell $(53.1 \%$ vs. $84.4 \%$; $p=0.002)$, supra bulla frontal cell $(37.5 \%$ vs. $59.4 \%$; $p=0.036)$, and supra orbital ethmoid cell ( $43.8 \%$ vs. $81.3 \%$; $p=0.001$ ) improved significantly from baseline to after 2 weeks, among residents (Figure 2). Frontal septal cell correctly classified by $18.8 \%$ residents and this rate improved significantly to $37.5 \%$ at 2 weeks $(p=0.001)$. The overall rate of correct classification among residents improved from $34.4 \%$ at baseline to $43.8 \%$ at 2 weeks ( $p=0.036$ ) (Figure 3 ).

There were no age-related or gender-related differences in the classification of air cells (Table 4). That is, $52.9 \%$ of residents above 30 years had a good classification score compared to $33.3 \%$ of residents below the age of 30 years $(p=0.265)$. In addition, $66.7 \%$ of female residents had good classification score compared to $38.5 \%$ of males $(p=0.209)$. R5 residents had significantly better classification score than R4 residents (60\% vs. $24.9 \%$; $p=0.049)$. Cronbach's alpha, a reliability measure, was 0.985 , with a number of items equal 32. Intraclass correlation coefficient, another measure of reliability, was significant for most questions for the 32 raters (Appendix 2). The average correct response rate was $50 \pm 25.7$ for the first questionnaire and $62.54 \pm 28.33$ for the second questionnaire.

Discussion. In 1905, Turner ${ }^{6}$ claimed the nonrecognition of one or more diverticula or recess 
IFAC inter and intra-rater reliability ... Assiri et al

Table 2 - Agreement rate for different items of the International Frontal Sinus Anatomy Classification (IFAC).

\begin{tabular}{|c|c|c|c|}
\hline Attitude item & Baseline & After 2 weeks & $P$-value* \\
\hline The IFAC easy to understand & $16(50.0)$ & $20(62.5)$ & 0.056 \\
\hline The IFAC can be applied clinically & $13(40.6)$ & $22(68.8)$ & $0.035 \dagger$ \\
\hline The IFAC is an important tool to understand the frontal sinus endoscopic operation step approach & $12(37.5)$ & $23(71.9)$ & $0.001 \dagger$ \\
\hline The IFAC aid a consistent communication between otolaryngologist residents & $13(40.6)$ & $23(71.9)$ & $0.002 \dagger$ \\
\hline $\begin{array}{l}\text { Comprehensive understanding of the IFAC would decrease the complication related to endoscopic frontal } \\
\text { sinus surgery }\end{array}$ & $12(37.5)$ & $21(65.6)$ & $0.012 \dagger$ \\
\hline $\begin{array}{l}\text { Comprehensive understanding of the IFAC would decrease frontal cell retain rate and decrease frontal sinus } \\
\text { disease recurrence rate }\end{array}$ & $17(53.1)$ & $19(59.4)$ & 0.241 \\
\hline The IFAC should be part of otorhinolaryngology curriculum training & $20(62.5)$ & $20(62.5)$ & 1.000 \\
\hline The IFAC better than other frontal cell classification kuhan classification & $13(40.6)$ & $15(46.9)$ & 0.352 \\
\hline
\end{tabular}

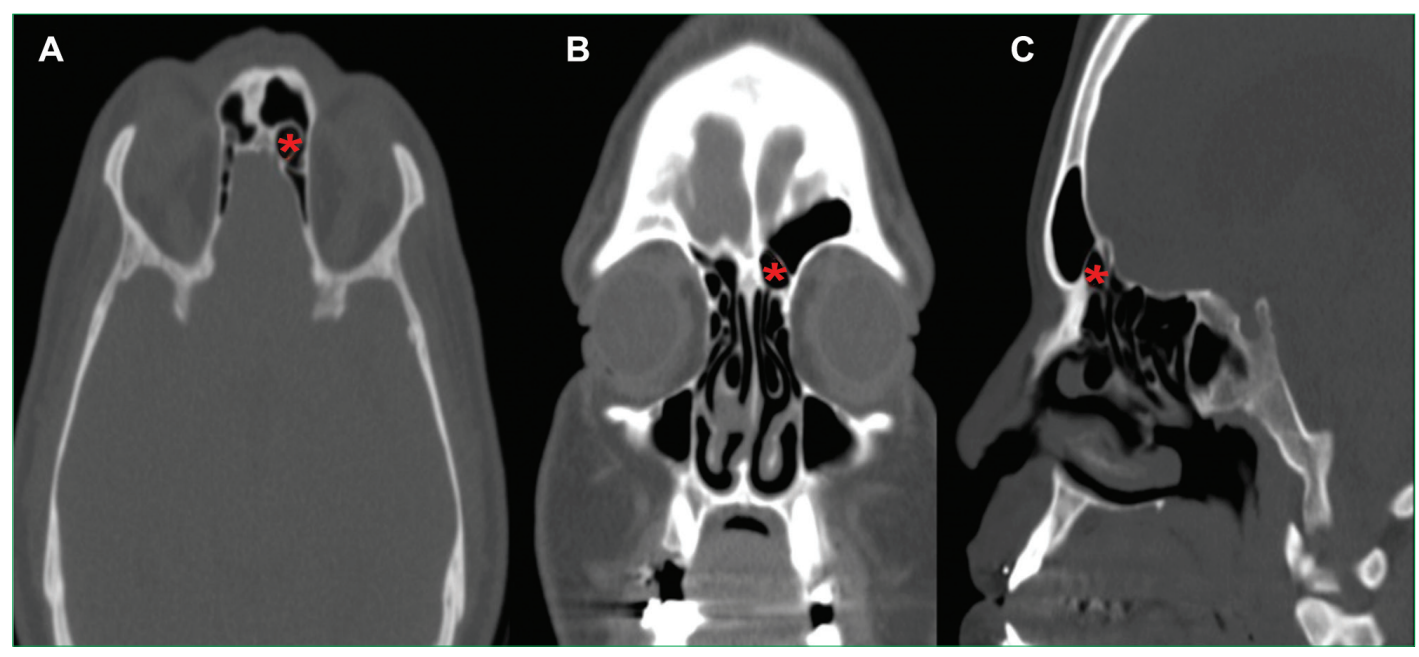

Figure 2 - Computed tomography scan of frontal septal cell showing the A) axial plane, B) coronal plane, C) sagittal plane .

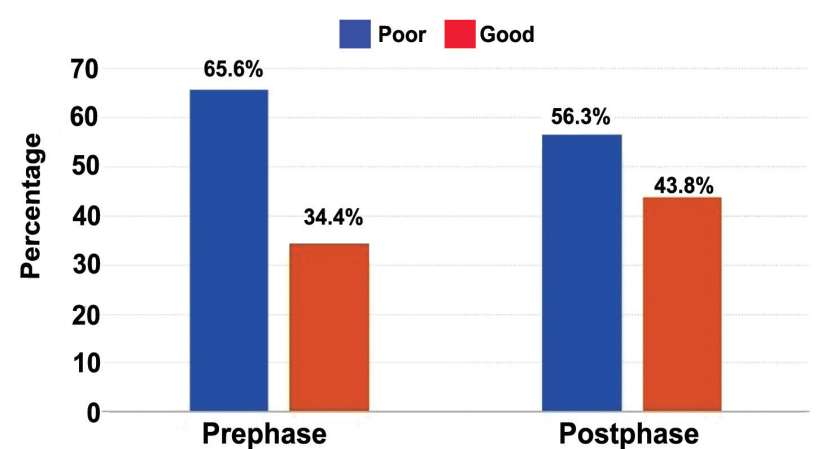

Figure 3 - Overall classification accuracy for the different images using the International Frontal Sinus Anatomy Classification. Poor: score $=$ less than $60 \%$; good: score $=60 \%$ or more.
Table 3 - Correct image classification by otorhinolaryngology-head and neck surgery senior residents.

\begin{tabular}{lccc}
\hline Image & Baseline & After 2 weeks & $P$-value* \\
\hline Image 1 & $29(90.6)$ & $31(96.9)$ & 0.715 \\
Image 2 & $17(53.1)$ & $28(87.5)$ & 0.002 \\
Image 3 & $14(43.8)$ & $26(81.3)$ & 0.001 \\
Image 4 & $17(53.1)$ & $27(84.4)$ & 0.002 \\
Image 5 & $12(37.5)$ & $19(59.4)$ & 0.036 \\
Image 6 & $14(43.8)$ & $26(81.3)$ & 0.001 \\
Image 7 & $6(18.8)$ & $12(37.5)$ & 0.001 \\
\hline
\end{tabular}

Values are presented as numbers and percentages (\%). *Mc-Nemar test, significant $p$-values are in bold 
Table 4 - Distribution of correct image classification based on otorhinolaryngology-head and neck surgery senior resident characteristics.

\begin{tabular}{|c|c|c|c|}
\hline \multirow{2}{*}{ Characteristics } & \multicolumn{2}{|c|}{ Image classification } & \multirow{2}{*}{$P$-value* } \\
\hline & Poor & Good & \\
\hline \multicolumn{4}{|l|}{ Age } \\
\hline$<30$ years & $10(66.7)$ & $5(33.3)$ & 0.265 \\
\hline$>30$ years & $8(47.1)$ & $9(52.9)$ & \\
\hline \multicolumn{4}{|l|}{ Gender } \\
\hline Male & $16(61.5)$ & $10(38.5)$ & 0.209 \\
\hline Female & $2(33.3)$ & $4(66.7)$ & \\
\hline \multicolumn{4}{|l|}{ Residency level } \\
\hline $\mathrm{R} 4$ & $12(70.6)$ & $5(29.4))$ & $0.049 \dagger$ \\
\hline R5 & $6(40.0)$ & $9 \quad(60.0$ & \\
\hline
\end{tabular}

within the frontal sinus caused by incomplete bony septa as a potential reason for sinus surgery failure.

In 1941, Van Alyea ${ }^{7}$ explained that "frontal cells" are air cells that extend to the frontal sinus from the frontal recess. Numerous recent studies agree that frontal recess is the "key" area for the management of frontal sinus disease. In 1993, Bent et $\mathrm{al}^{8}$ classified the frontal recess cells into 3 frontal cell types (types $1-4$ or K1-K4), which was later on adjusted by Wormald and Chan ${ }^{9}$ in 2003 (Appendix 3). Lee et $\mathrm{al}^{10}$ proposed the frontal recess pneumatization criteria for aiding endoscopic sinus surgery; and characterized the supra bulla cell (SBC) and frontal bulla cell (FBC), which were poorly described before. Wormald et $\mathrm{a}^{11}$ described the IFAC system (Appendix 1) and named each cell according to its anatomic position. This allowed easy communication between surgeons and presented clear anatomy of the frontal sinus.

Wormold $^{12}$ emphasized that agger nasi cells, with a prevalence of $94 \%$, were crucial for understanding the anatomy of the frontal recess. In a review of more than 200 CT scans of the paranasal sinuses, Bolger et $\mathrm{al}^{13}$ found that approximately $98.5 \%$ of patients had the agger nasi cells. In addition, Eweiss and Khali ${ }^{14}$ reported a prevalence of $78.571 \%$ for frontal cells. Various modalities are used to identify the cells. On 3 dimensional images of the frontal sinus and frontal recess, each cell around the area must be identified first on the coronal and parasagittal scan. ${ }^{15}$ In a study involving approximately 100 scans for a small group of raters, Choby et $\mathrm{al}^{16}$ reported a median ICC of 0.80 or significant inter-rater reliability for the IFAC system. Meyer et $\mathrm{al},{ }^{17}$ found a markedly elevated incidence of frontal sinus disease in the presence of type III and IV frontal cells. One a recent study, both the inter- and intra-rater reliability for the IFAC system between 15 international groups of rhinologist fellows. Raters who used IFAC showed superior agreement over raters who used modified Kuhn classification of frontal ethmoidal cells to classify frontal cells $(\kappa=0.7248-1.0$ vs. $\kappa=0.249$ $0.3 .^{5}$

The study has evaluated the agreement between 32 ORL-HNS senior residents while employing IFAC to classify frontal cells. More than $65 \%$ of residents found IFAC clinically applicable, more than $70 \%$ considered it a tool that aids consistent communication between surgeons, and approximately $65.6 \%$ of residents agreed that it was essential to understand the classification system. Most residents (75\%) agreed on the classification of a marked cell in most of the CT images. However, the agreement for the frontal septal cell was the lowest $(37.5 \%)$. Some variations in agreement occurred for the CT scan with a marked supra bulla frontal cell, where approximately $60 \%$ of residents (19 of 32) agreed, and the remaining 13 raters classified it as a supraorbital ethmoid cell. The overall correct classification among residents significantly improved from $34.4 \%$ to $43.8 \%$. R5 residents (60\%) scored significantly better than R4 residents $(24.9 \%)$.

It is worth mentioning that approximately $30 \%$ of participants had negative attitudes towards IFAC in the second questionnaire. This may be attributed to the fact that the IFAC is not yet a standard to follow. Residents may argue that specialists' perspectives could be misleading owing to the potential bias and the absence of generalizability. ${ }^{18}$ In different specialties, proposed imaging-based classifications have been set as a standard by confronting them with the intraoperative findings. Nonetheless, this may be challenging since the frontal recess is a small area. For better validation and reliability, a recent study has suggested that the IFAC should be compared with other classifications based on the findings from endoscopic sinus surgeries, along with enrolling a representative sample. ${ }^{5}$ Thus, the authors of the present research believe that the current study has been limited by a small sample size and being carried out at a single center. Future large-scale studies are needed to clarify and to establish conclusive evidence.

In conclusion, the anatomic location of the frontal sinus poses surgical challenges. Inadequate sinus treatment causes the failure of drainage in the case of CRS. A good understanding of the IFAC system by surgeons will circumvent major and minor complications. The purpose of the IFAC, according to the principle investigators, was to provide a thorough view of the anatomy, enable better communication between surgeons, and teach the necessary EFSS steps 
accurately. An elaborate checking of frontal recess anatomy using thin CT sections is vital for the surgeons performing EFSS.

Acknowledgment. This project was supported by King Saud University, Deanship of Scientific Research, College of Medicine Research Center, Riyadh, Saudi Arabia. The authors are grateful for the support by the Deanship of Scientific Research, Prince Sattam Bin Abdulaziz, University, Alkharj, Saudi Arabia. We would like to thank Editage (www.editage.com) for English language editing.

\section{References}

1. Jankowski R, Gallet P, Nguyen DT, Rumeau C. Chronic rhinosinusitis of adults: new definition, new diagnosis. Rev Prat 2019; 69: 274-278.

2. Lou H, Zhang N, Bachert C, Zhang L. Highlights of eosinophilic chronic rhinosinusitis with nasal polyps in definition, prognosis, and advancement. Int Forum Allergy Rhinol 2018; 8: 1218-1225.

3. Ertugay ÖÇ, Toros SZ, Zhang L. Chronic Rhinosinusitis: Adults and Children. In: Cingi C, Muluk NB. editors. All Around the Nose. Switzerland (AG): Springer Nature; 2020. p. 213-220.

4. Passali D, Cingi C, Cambi J, Passali F, Muluk NB, Bellussi ML. A survey on chronic rhinosinusitis: opinions from experts of 50 countries. Eur Arch Otorhinolaryngol 2016; 273: 2097-2109.

5. Villarreal R, Wrobel BB, Macias $\triangle$ Valle LF, Davis GE, Prihoda TJ, Luong AU, et al. International assessment of inter冈and intrarater reliability of the International Frontal Sinus Anatomy Classification system. Int Forum Allergy Rhinol 2019; 9: 39-45.

6. Turner AL. The operative treatment of chronic suppuration of the frontal sinus, with special reference to the method of Killian. Trans Med Chir Soc Edinb 1904; 23: 249-251.

7. Van Alyea OE. Frontal cells: an anatomic study of these cells with consideration of their clinical significance. Arch Otolaryngol 1941; 34: 11-23.
8. Bent JP, Cuilty-Siller C, Kuhn FA. The frontal cell as a cause of frontal sinus obstruction. Am J Rhinol Allergy 1994; 4: 185-191.

9. Wormald PJ, Chan SZ. Surgical techniques for the removal of frontal recess cells obstructing the frontal ostium. Am J Rhinol 2003; 17: 221-226.

10. Lee WT, Kuhn FA, Citardi MJ. 3D computed tomographic analysis of frontal recess anatomy in patients without frontal sinusitis. Otolaryngol Head Neck Surg 2004; 131: 164-173.

11. Wormald PJ, Hoseman W, Callejas C, Weber RK, Kennedy DW, Citardi MJ, et al. The International Frontal Sinus Anatomy Classification (IFAC) and Classification of the Extent of Endoscopic Frontal Sinus Surgery (EFSS). Int Forum Allergy Rhinol 2016; 6: 677-696.

12. Wormald PJ. The agger nasi cell: the key to understanding the anatomy of the frontal recess. Otolaryngol Head Neck Surg 2003; 129: 497-507.

13. Bolger WE, Butzin CA, Parsons DS. Paranasal sinus bony anatomic variations and mucosal abnormalities: CT analysis for endoscopic sinus surgery. Laryngoscope 1991; 101: 56-64.

14. Eweiss AZ1, Khalil HS. The prevalence of frontal cells and their relation to frontal sinusitis: a radiological study of the frontal recess area. ISRN Otolaryngol 2013; 2013: 687582.

15. Wang P, Yang G, Han X, Zhang Y, Lan J, Zhao H, et al. Study of frontal recess anatomy based on three-dimension computed tomography images reconstruction in Chinese subjects without frontal sinus disease. Int J Clin Exp Med 2016; 9: 18912-18920.

16. Choby G, Thamboo A, Won TB, Kim J, Shih LC, Hwang $\mathrm{PH}$. Computed tomography analysis of frontal cell prevalence according to the International Frontal Sinus Anatomy Classification. Int Forum Allergy Rhinol 2018; 8: 825-830.

17. Meyer TK, Kocak M, Smith MM, Smith TL. Coronal computed tomography analysis of frontal cells. Am J Rhinol 2003; 17: 163-168.

18. James D, Warren-Forward H. Research methods for formal consensus development. Nurse Res 2015; 22: 35-40. 
IFAC inter and intra-rater reliability ... Assiri et al

Appendix 1 - International Frontal Sinus Anatomy Classification.

\begin{tabular}{|c|c|c|}
\hline Frontal air cell effect on FSDP* & Cell name & Definition \\
\hline \multirow{3}{*}{$\begin{array}{l}\text { Anterior air cells push } \\
\text { FSDP medial, posterior, or } \\
\text { posteromedial }\end{array}$} & Agger nasi cell (ANC) & $\begin{array}{l}\text { Anterior to the origin of middle turbinate or above the most anterior } \\
\text { insertion of middle turbinate into the lateral nasal wall. }\end{array}$ \\
\hline & Supra agger cell (SAC) & $\begin{array}{l}\text { Anterior-lateral ethmoidal cell above ANC that does not pneumatize into } \\
\text { the frontal sinus. }\end{array}$ \\
\hline & Supra agger frontal cell (SAFC) & $\begin{array}{l}\text { SAC that extends into the frontal sinus (wide range of sizes from floor up to } \\
\text { the roof of the frontal sinus). }\end{array}$ \\
\hline \multirow{3}{*}{$\begin{array}{l}\text { Posterior air cells push FSDP } \\
\text { anterior }\end{array}$} & Supra bulla cell (SBC) & Above bulla ethmoidalis; does not enter frontal sinus. \\
\hline & Supra bulla frontal cell (SBFC) & $\begin{array}{l}\text { SBC that pneumatizes along skull base to the posterior frontal sinus. The } \\
\text { skull base forms the posterior wall of the cell. }\end{array}$ \\
\hline & Supraorbital ethmoid cell (SOEC) & $\begin{array}{l}\text { Anterior ethmoid cell pneumatizing around, anterior, or posterior to } \\
\text { anterior ethmoidal artery over the roof of the orbit. Often forms part of the } \\
\text { posterior wall of extensively pneumatized frontal sinus separated only by } \\
\text { bony septation. }\end{array}$ \\
\hline $\begin{array}{l}\text { Medial air cells push FSDP } \\
\text { lateral }\end{array}$ & Frontal septal cell (FSC) & $\begin{array}{l}\text { The medially based cell of anterior ethmoid or inferior frontal sinus; } \\
\text { attached or located in interfrontal sinus septum; associated with the medial } \\
\text { aspect of the frontal sinus outflow tract, pushing FSDP laterally and } \\
\text { frequently posteriorly. }\end{array}$ \\
\hline \multicolumn{3}{|c|}{ *frontal sinus drainage pathway } \\
\hline
\end{tabular}

Appendix 2 - Two-way mixed effect model where people effects are random and measures effects are fixed.

\begin{tabular}{lccccccc}
\hline Measures effects & $\begin{array}{c}\text { Intraclass } \\
\text { correlation }^{\mathrm{b}}\end{array}$ & \multicolumn{2}{c}{$95 \% \mathrm{CI}$} & \multicolumn{3}{c}{ F test with true value 0 } \\
& Lower band & Upper band & Value & Df1 & Df2 & Difference \\
\hline Single measure & $0.661^{\mathrm{a}}$ & 0.498 & 0.837 & 66.523 & 13 & 403 & 0.000 \\
Average measure & $0.984^{\mathrm{c}}$ & 0.969 & 0.994 & 66.523 & 13 & 403 & 0.000 \\
\hline
\end{tabular}

${ }^{a}$ The estimator is the same, whereas the interaction is present or not. ${ }^{b}$ Type A intraclass correlation coefficients using an absolute agreement definition. 'This estimate is computed assuming the interaction effect is absent, because it is not estimable otherwise.

Appendix 3 - Modified Kuhn classification of frontal ethmoidal cells.

\begin{tabular}{ll}
\hline Name & Description \\
\hline Agger nasi cell (ANC) & Usually a single cell anterior to the middle turbinate \\
Supraorbital ethmoid cell (SOEC) & SBC protruding into the orbital roof \\
Frontoethmoidal cells (Bent and Kuhn & cells close or within the frontal process of the maxillary bone and above the ANC \\
frontal cells) & \\
K1 & Single frontal recess cell above ANC \\
K2 & Tier of cells in the frontal recess above ANC \\
K3 & Single massive cell pneumatizing cephalad into frontal sinus occupying $<50 \%$ of vertical sinus \\
Height K4 & Single isolated cell within the frontal sinus occupying $>50 \%$ of vertical sinus height \\
Supra bulla cell (SBC) & A cell or cells above the bulla ethmoidalis \\
Frontal bulla cell (FBC) & SBC protruding into frontal sinus \\
Interfrontal sinus septal cell (ISSC) & Cell resulting from pneumatization of interfrontal sinus septum pushing FSDP laterally and narrowing the \\
& frontal ostium
\end{tabular}

